\title{
On the Civil Liability for Acts of Violating Personal Information
}

\author{
Shan $\mathrm{WU}^{1, \mathrm{a},{ }^{*}}$ \\ ${ }^{1}$ North China Electric Power University of Bao Ding city in He Bei Province, China \\ a460973737@qq.com \\ ${ }^{*}$ Corresponding author
}

Keywords: violation of personal information, liability, Civil Protection

\begin{abstract}
Personal information as a strategic resource of the most valuable in the 20th century, the importance of it does not have words to say. However, our country has no a "Personal Information Protection Law "to regulate the collection, processing and use of information, often resulting in an embarrassing situation in reality. Because of the many types of liability act in violation of the personal information, and civil law contact our daily lives most closely, so this passage introduce personal information through a clear connotation and extension as well as its constituent elements, focuses on civil liability for acts of violation of personal information in the tort liability and breach of contract, combined with the recently revised "Consumer Protection Law" briefly introduce special areas of personal information protection issues.
\end{abstract}

\section{Introduction}

In our daily lives, "Information fall "common occurrences, spam, harassing messages and various targeted advertising filled every corner. June 2008, Shenzhen's " leak disc " incident , the CCTV "3 - 15" party exposure mobile operators sell personal information, and many other online banking transactions sensational event so we are deeply worried about the information protection of personal information society. Also, due to the violation of the legal relationship of personal information involved with complex behavior, which also has responsibility for the type of diversity, including civil liability, criminal and administrative responsibility, which the Civil Protection of individual rights is a vital standard of all members of the community interest, so this is mainly to civil liability as a starting point to explore the behavior of the responsibility borne invasion of personal information.

\section{Chapter One: the connotation and extension of personal information}

Clear connotation and extension of personal information is not only the object of legal protection as a prerequisite and foundation, but also to prevent excessive protection of information and hinder the objective requirements of the flow of information. As China's information law by Professor Zhou Hanhua said: "If the protection of personal information into the extreme is bound to make everyone become a seat ' information islands ', the whole society into a mess." Seen in this light, the range of personal information is essential.

From legislation relating to the world of personal information, the definition of personal information varies from one to another. EU countries are mostly used in the definition of the EU Directive 95 , used the " personal data " in the title, and using methods defined connotation , characteristics of personal data will be a high degree of generalization ; from the United States, " Privacy Act" can be seen in the definition of personal information in the United States is " personal 
privacy " and define the way using a combination of connotation and extension, as well as with the United States adopted the 1981 Israeli " Privacy Law" legislation of the same , 1987 Canadian " Privacy Act " and the 1988 Australian " Privacy Act "; Japan 2003 "Personal Information protection Act , "the use of " personal information " in the title and content plus the extension of the definition of the way, it is also similar with in 1977 , Germany has developed " the federal personal Information Protection Law" , in 1978 Austria " data Protection Act " and the British " automatic processing of personal information and its use in civil law norms " ; while China's Taiwan region , " computer-Processed Personal data Protection Act " is used in " the term personal data . "

Models from Chinese scholars on the definition of personal information (information relating to individuals) is made: the sum of all possible information to identify himself, this information includes a person's physical, psychological , intellectual , individual, social , economic , cultural , family, etc. Thus, China's legislation on the definition of personal information "personal information" should be used to define the concept of the way of combining the connotation and extension to the development of society to give better protection of personal information.

Although the title and definition methods used in these countries and regions are different, but one of the core content is the same, from the legislation of each country, we can summarize the constituent elements of personal information, including the substantial elements and form elements.

\section{First: substantial elements}

Substantial elements constitute the essential elements of personal information, substantial elements of personal information constitutes a " recognition" that a person can be critical of another person 's personal information and the phase difference, and that this information should be direct or indirect recognition a person 's information. I can identify personal information such as identity card numbers, portrait, DNA, and indirectly personally identifiable information that can not identify a single, only to be combined with other personal information identifiable information, such as a person's occupation, education, hobbies interest . Including all the personal information of the direct and indirect personal identification information .

\section{Second: the formal requirements}

Form elements constitute personal information in the form of conditions that must be met , including fixed and can be handled. The former refers to the personal information is not to say it 's some information out of thin air, it must be attached to a certain carrier exists. America's " Privacy Act " and the German " Federal Personal Data Protection Act" provide for information must have a certain picture and sound recording ; latter refers to personal information must be in a certain way can access, retrieve and perform other processes, which can be seen from China's Hong Kong in 96 cases, if the information is not processed and the use of man, then this information will not play a role, it can not be the personal Information Protection Act protected object .

\section{Chapter Two: civil liability for acts of violation of personal information}

Information about the violation of personal civil liability for acts, most of the world countries and theorists are mostly concerned about the content of tort liability for breach of contract rarely involved. But with the development of market economy, the personal information of this important resource is gradually entering the market to trade, and in the course of trade in violation of the personal information of behavior occurs may also result in breach of contract, so this article from tort liability and breach of contract responsibility both to illustrate the behavior of civil liability for violations of personal information . 


\section{First: violation of personal information behavior of tort liability}

Fig. 1: the responsibility principle

Infringement of personal information, the responsibility principle is also living in the same central position, determines the constituent elements of tort liability, sharing the burden of proof , exemptions and methods of determining damages. Theoretically speaking, the imputation principle of fault liability tort can be divided into no-fault principle . Legislation of some countries and regions of the world in the main distinction between acts of violation of personal information public bodies and non- government agency, in order to determine the different responsibility principle . For example, the relevant provisions of Taiwan's " Information Law" and the German "Federal Personal Information Protection Act " have, in our personal information legislation is concerned, the above example is a reference legislation meaningless. Responsibility principle should not be generalized, but should apply to different subjects according to their different characteristics responsibility principle. On the one hand, for public authorities, as the body has a public authority , so strict liability should be imposed, that the principle of no- fault liability . The other hand, taking into account the information society for the flow of information requirements, in order to create a relaxed some of the emerging industry of legal environment, for non- fault liability principle applies to public authorities.

Fig. 2: Elements in violation of personal information behavior

It including violations, damage to the facts, subjective fault and the causal link .

Violations

Illegal invasion of personal information in accordance with their different behavior can be divided into acts and omissions. Our newly revised "Consumer Protection Law" can be used as a reference .

Damage Facts

In the field of personal information, if it is an individual or organization to illegal methods to collect personal information not be made public, without causing damage to the facts, then it should not constitute infringement.

Subjective fault

Here is a case of infringement focuses on the main non-public institutions, as mentioned above , public authorities infringement imputation principle is no-fault liability, then the fault is no substantial presence in terms of its significance. For the purposes of the non-government agency, the fault is divided into intentional and negligent. The former, such as illegal collection, use personal information to others, which, as due to the deal failed to fulfill the main information necessary security obligations lead to the disclosure of personal information, lost. These can constitute a violation of personal information behavior of subjective fault .

Causal link

Here's a causal link, once established, would mean the establishment of personal information violations, the corresponding tort liability also established appropriate .

Fig. 3: exemptions

Commonly used exemptions have legally enforceable duties, self-defense, emergency refuge , the victim's consent, the victim intentionally, the third person at fault and force majeure . For violation of personal information act exemptions, I think we can be identified with specific situations according to common law tort defenses. For example, the body agreed to adopt information and the public interest .

Fig. 4: violation of personal civil liability information behavior

We often say "no relief, no rights." Indeed, no matter how perfect the design of substantive law , 
if there is no corresponding supervise relief measures are likely to become a piece of paper talk . Therefore, countries are supervised relief measures prescribed in the legislation, with the traditional relief afterwards different privacy protection, personal information protection should focus on prevention beforehand that regulate the collection of personal information from the source , processing and use. For example, many countries have personal information protection prior regulatory agencies, and personal information on the collection, processing, use for review. Of personal information legislation can draw on this measure, the violation of personal information in advance to prevent the behavior .

In addition to advance the prevention, relief afterwards is essential. China's " Civil Law" Article 134 of the civil liability provisions of the ten ways, including stopping the damage ; removal of obstacles ; eliminate the danger ; return of property ; restitution ; repair , rework or replacement; damages ; pay liquidated damages ; elimination the impact of rehabilitation and an apology. Acts of infringement of personal information, in view of the characteristics of the intangible nature of the personal information, ways to apply the main responsibility is to stop the infringement, damages, eliminate the impact of rehabilitation and an apology.

Among them, the main responsibility for damages way. For the determination of the amount of compensation, in terms of compensation for property damage, I think we can learn from Japan, the relevant provisions of the legislation : For illegal gathering, the use of personal information, the parties may use personal information obtained in accordance with the interests of the infringer, or the loss suffered request compensation for loss of profits gained by the infringer or the victim can not be determined, it shall bear civil liability in accordance with the circumstances. Some scholars believe that the principle of full compensation should adopt specific property damages calculation methods and standards can refer to the relevant provisions of the Supreme Court "to hear disputes involving computer network copyright Specific Application of Laws in interpretation" . For compensation for moral damage due to violation of personal information is essentially moral rights infringement on personal information, so should the victim damages spiritually. The amount of compensation shall include compensation for moral damage compensation and other losses due to mental suffering personal information subject to the mental anguish caused by the body due to personal information personal information being caused and suffered violations, such as treatment costs, loss of fees .

\section{Second: acts of infringement liability for breach of personal information}

Personal information with attributes so you can enter the property market transactions, where transactions can be divided into two cases, one case is the use of personal information for the purpose of people with commercial interests, using the license to use, transfer or exchange of personal information and other ways to pay to a third person's behavior, mainly among those legitimate uses of personal information with third parties, there is no corresponding contractual relationship between them and the message body, and not breach occurs, but may occur on the message body tort liability; another case is the subject of personal information for the purpose to obtain benefits I will sell your personal information to collect people's behavior . Occur directly between the information collected human body and may occur in violation of one of the parties to the contract, resulting in cases of breach of contract .

With the gradual development of market economy, acts of infringement liability for breach of personal information will be more and more attention, so the development of our country "Personal Information Protection Act ," the form of this responsibility should not be ignored . 


\section{Chapter Three: the protection of personal information in specific areas}

Different sectors of the utilization of personal information is different, and therefore develop special rules for specific industries is universal practice, some special industries such as personal credit information industry, medical information processing. Because of the newly revised " Consumer Protection Law" to the operators involved in the collection, processing and use of consumers' personal information with the relevant rules, especially as an example in this article, a brief discussion.

In online shopping, and other new consumer environment, the importance is magnified even more personal information. The reason is that the online shopping process operators of any link from the site 's operator, to businesses, to the courier company can easily get to the personal information of consumers. Thus, the illegal sale, reselling personal information emerging phenomenon, phone, e-mail messages in the spam messages and it is illegal to use, disclosure of personal information by the negative consequences. Given the grim situation facing the protection of personal information under the new circumstances, China's new "Consumer Law" provisions made from four aspects: First, consumers purchase and use of goods or receiving services, enjoy the right to a name, portrait, privacy such as the right to protection of personal information rights . Secondly, operators collect, use consumers' personal information, should follow the legal, legitimate and necessary principles, express collect information purposes, methods and scope, and by the consent of the collectors. Third, the operators and their staff to collect personal information on consumers must be kept strictly confidential , and shall take technical measures and other measures necessary to ensure information security. Fourth, the operator or the request without the consent of the consumer or the consumer expressly rejected not to send commercial electronic information .

"Consumer Protection Law" and the implementation of the relevant provisions of the Personal Information Protection can be made for the development of China's "Personal Information Protection Act " to provide some reference. In addition to the field of business spending on new legislation of personal information, the personal information of China's first since February 1, 2013 implementation of the protection of national standards - " Information Security Technology Public and Commercial Services Information Systems Personal Information Protection Guide " is not only You can raise public awareness of the protection of personal information, personal information protection control means and methods, can also provide a good reference for the legislation.

\section{References:}

[1]QI Aiming, "Saving the Information Society Personality : Personal Information Protection Law General " [M] Beijing : Peking University Press .2009

[2]HONG Hailing, "Study of Civil Protection of Personal Information " [M]. Law Press .2010

[3]SUN Changxing, Qin Jie," Personal Information Protection study legal issues " [J]. Beijing University of Posts and Telecommunications ( Social Science Edition ) .2010 Volume 12, February 1

[4]QI Aiming," Personal Information Protection Law Studies " [J]. " Hebei Law " .2008 April 26 No. 4

[5]Huang Hao," Personal Information Protection Legislation Mode "[D]. Fudan .2011

[6]DU Huihui, "On Civil Protection of Personal Information”[D].Shandong University .2008 
March

[7]Zhu Lingzhen, " Speed up legislation and standards, promote the development of the Personal Information Protection " [EB / OL]. " Information Security and Technology" in March 2012

[8]Wang Jing. " The first national standards to protect the personal information geometric effect " [EB / OL]. " Legal Daily" 004 Edition April 18, 2012

[9]Zhang Wei," Personal Information Protection Status worrying " [EB / OL]. " Guangming Daily" December 19, 2012 